VINE

$35,1 / 2$

58

\title{
Lessons and outcomes from the Subject Portals Project
}

\author{
Marieke Guy \\ UKOLN, University of Bath, Bath, UK
}

\begin{abstract}
Purpose - The paper proposes to investigate the purpose of the Subject Portals Project and the viability of using Open Source (OS).

Design/methodology/approach - The paper describes the Subject Portals Project.

Findings - The paper finds that the purpose of the Subject Portals Project was to enable the participating RDN hubs to become portals, implying an ability to integrate third-party content and provide customised use. Portal functionality is key to presentation of data to end users, and so also vital to the Information Environment concept. A supplementary approach is to create portable functions or portlets that can be incorporated into other services.
\end{abstract}

Originality/value - The paper is useful to those planning to implement Subject Portals Project.

Keywords Portals, Information retrieval, Further education, Higher education

Paper type Research paper

\section{Introduction to SPP}

The RDN Subject Portals Project (SPP) (www.portal.ac.uk/spp/) was funded by Joint Information Systems Committee (JISC) to improve the functionality of five participating RDN hub sites by developing them into subject portals. By doing so SPP will provide a subject-based presentational layer for the JISC Information Environment (IE) as well as additional services for RDN users.

In their simplest form, subject portals are aggregators of third party content that present end users with a tailored view of the web within a particular subject area. However, during the project it became clear that the development of alternative means of accessing content through institutional portals, virtual learning environments (VLEs), etc., would have an impact on the original focus for the creation of subject-based services. Therefore, in addition to creating these services, SPP's development strategy has been to create portable functionality, which could be embedded into a variety of other environments. This was achieved by the creation of a series of "portlets" designed to sit within a portal framework. The portlet approach means that the hubs have a choice of the functions they install, and the aim of the modular design is that the portlets developed will be non-framework specific and could be embedded in other portal environments.

The hub sites involved in SPP were BIOME (University of Nottingham) (http:// biome.ac.uk/)[1]; EEVL (Heriot Watt University, Edinburgh) (www.eevl.ac.uk/[2]; HUMBUL (University of Oxford) (www.humbul.ac.uk/)[3]; and SOSIG (University of

VINE: The journal of information and knowledge management systems Vol. 35 No. 1/2, 2005 pp. $58-63$

(C) Emerald Group Publishing Limited 0305-5728

DOI $10.1108 / 03055720510588498$ ukoln ac.uk/) at the University of Bath and the technical development was led by ILRT ukoln.ac.uk/) at the University of Bath and the technical development was led by ILRT at the University of Bristol (www.ilrt.bris.ac.uk/). PSIGate (University of Manchester) (www.psigate.ac.uk/)[5] and the Maths Portal Project (University of Birmingham) 
(www.eevl.ac.uk/mathematics/), funded separately under 5/99, also contributed to the project.

\section{Phase II: continued funding}

SPP was awarded further funding to focus on the installation, maintenance and continued technical development of the portal software. During phase II, which is running until August 2004, the portal prototype developed by SPP will be installed at the original participating RDN hubs and three additional hubs: ALTIS (Birmingham University) (www.altis.ac.uk/)[6]; ARTIFACT (Manchester Metropolitan University) (www.artifact.ac.uk/[7]; and GEsource (Birmingham University) (www.gesource.ac. uk/home.html)[8]. Throughout the first phase of the project the framework and the main portlet areas (cross-searching, user profiling and access management) were developed. Although these areas required further development, phase II concentrates on a number of additional aggregated services, namely newsfeeds, events and an e-journal search engine. This phase of the project also includes an investigation of how best to embed portal functionality within alternative third party portal environments, such as institutional portals and VLEs, and will make this technology Open Source for use within the wider community.

The SPP Project has now become part of the PORTALs Programme which is looking at various aspects of portals such as good practice in portal usage and how portals can and will be used inside and outside formal education. There will also be efforts to create a series of demonstrator portals in different areas (subject, format-based, community-based).

\section{Fitting into the IE}

In response to the current situation of multiple disparate information resources and services with different user interfaces, the JISC have agreed on a five-year strategy to create an IE. The IE aims to enhance the visibility of resources and the discovery of and access to content together with the provision of seamless discovery across multiple content providers. The "portal problem", which considers which interface users will use, is one of the most significant issues of the IE jigsaw and SPP has been aware of where and how it will fit in from the onset. Subject portals, by providing the end-user with a discipline or topic-specific view of available resources are a key component of the presentation layer services. SPP portal services will sit at the RDN hubs and will broker information to the user while relying on many of the supporting shared infrastructure services (see Figure 1).

SPP is keen to fit into the IE smoothly and all work and software developed has been undertaken in accordance with the IE-specified technical guidelines and standards in mind (see Figure 2).

For example:

- Web site. The SPP web site is in xhtml 1.0, uses cascading style sheets and aims to be accessible and standards-compliant.

- Distributed searching. Z39.50 is supported and in the future support for other network protocols will be investigated. Work has also been done with the Join-up projects Xgrain (http://edina.ac.uk/projects/joinup/xgrain/) and ZBLSA (www. edina.ac.uk/projects/joinup/zblsa/) to explore the feasibility of providing access

\section{The Subject \\ Portals Project}


VINE

$35,1 / 2$

60

Figure 1.

How portals fit into the JISC Information Environment

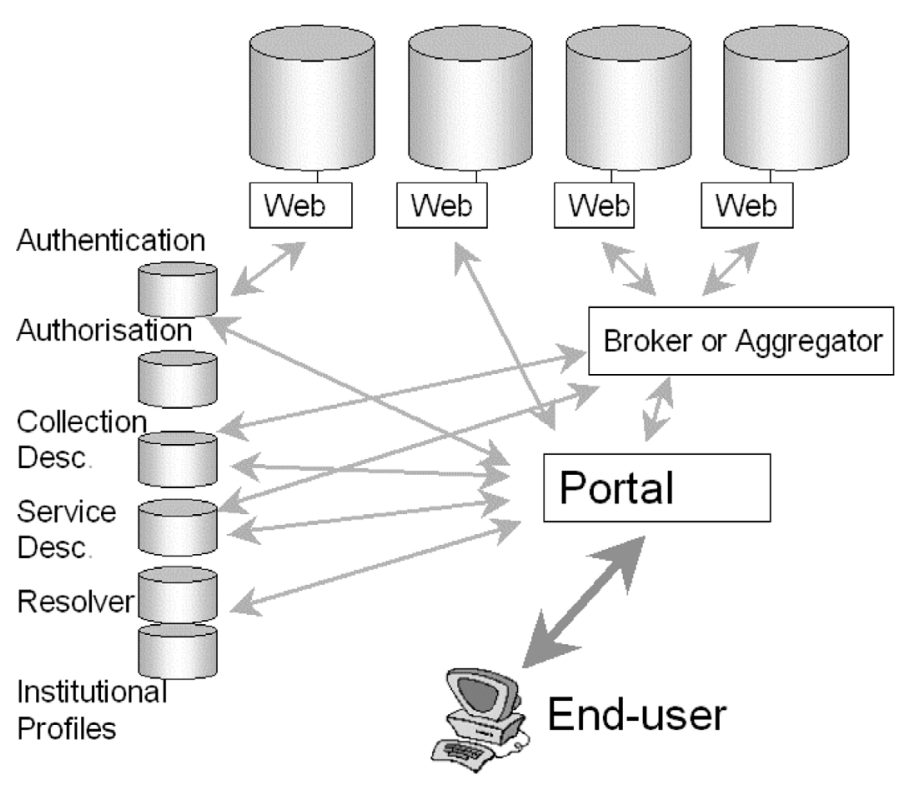

to their services via the portal. At the moment trial access to both services has been added and improving this will be an area of work for the future.

- Newsfeeds. The RSS 1.0 format has been investigated for use by the prototype event newsfeed. XSLT was used to manage the display of the newsfeed data.

- Authentication and authorisation. The authentication support developed for SPP was based on the Java Authentication and Authorisation Service (JAAS), which follows the Pluggable Authentication Mechanism (PAM) standard. The two Login Modules to authenticate users against the local AMS and the Athens access management system were developed using the Java Naming and Directory Interface (JNDI) and the Java API for Athens, respectively.

\section{Legacy for the UK higher education and further education communities}

SPP has had many positive outcomes, some expected and others serendipitous. The major deliverables of the project are obviously the software developed. The real benefits of this software will be seen when rolled out for further testing at the hubs this year. The current state of development can be experienced through the SPP Demonstrator (www.portal.ac.uk/spp/demo/) now available. The other most significant lessons learned that may be of benefit to the UK higher education (HE) and further education $(\mathrm{FE})$ community are the following.

\section{Managing a distributed team}

During the first phase of the project a crucial factor in the success of the work carried out was the setting up and management of a distributed team, including a core technical development group (Guy, 2004). Geographically distributed projects are always a challenge in terms of project management and a variety of tools and methods 


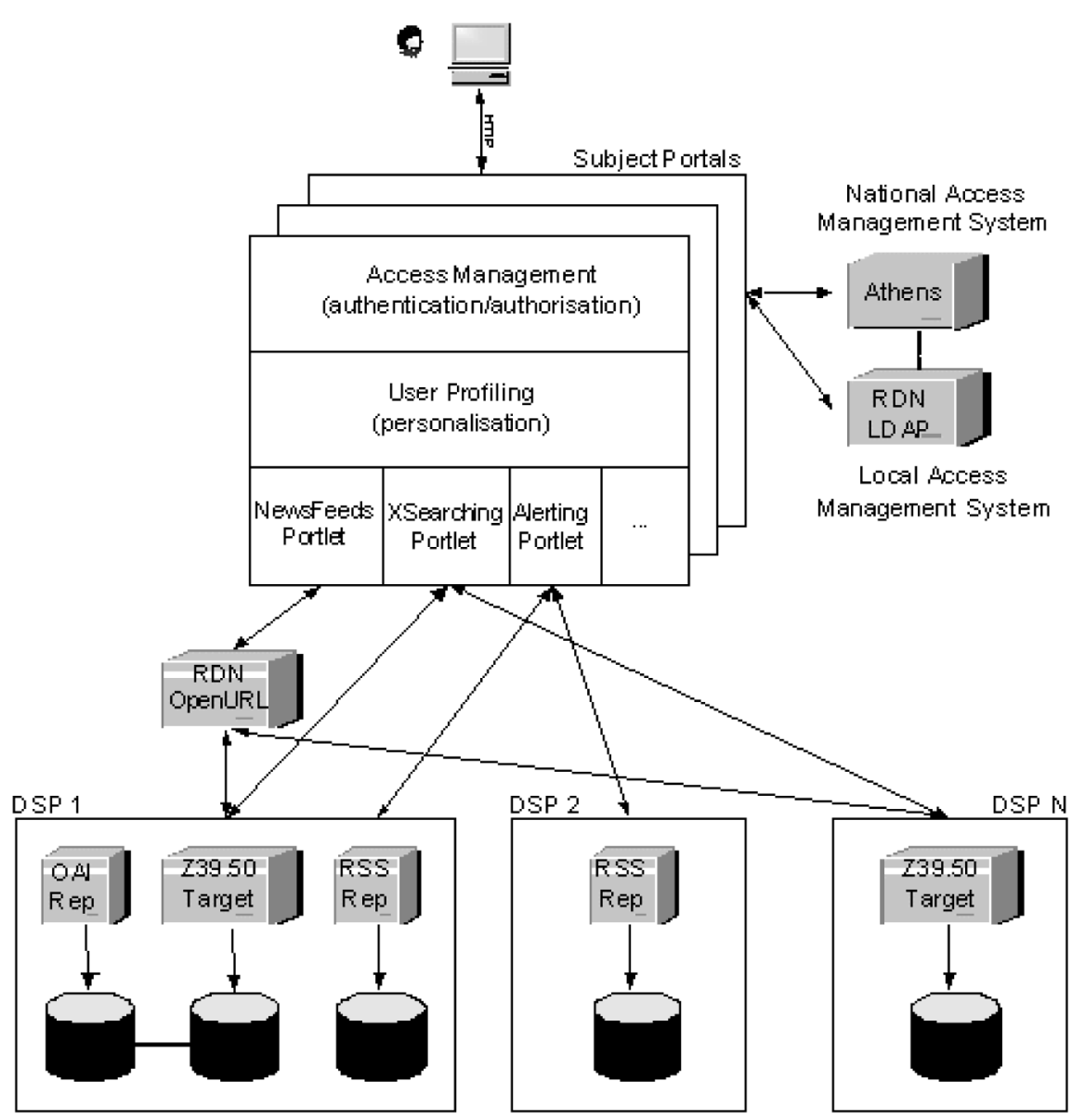

The Subject
Portals Project

National Acoess

Wanagerment Systerm

61

(asthentication/authorisation)

User Protiling

personalisation)

RDN

Local Acoess

anagement System

Figure 2. SPP architecture

were successfully used to aid the process. For example, the technical developers, who were distributed over five sites, needed to be able to keep in regular contact. This was managed by using a variety of methods and tools, including the use of Internet Relay Chat (IRC) and a developers' web site. The distributed team also benefited from a knowledge survey held early on in the project across the participating sites. The completed skill sets were used as a planning tool to enable people to be matched to tasks. Individual preferences to work in certain areas were also taken into account in order to obtain maximum satisfaction across the group.

The Concurrent Versions System (CVS) was a cornerstone of the infrastructure needed to support distributed software development, allowing multiple developers to work on the same code base simultaneously. Another key infrastructure tool was a build environment that took care of standard tasks, allowing the team members to concentrate on their coding. Such a system was built using a combination of Open Source and freely available tools. The distributed team also made use of UML design methodology, which has resulted in a JISC-wide interest in using it across similar 
VINE

$35,1 / 2$

62 projects. A structured approach to software development was considered essential, especially when working with a geographically dispersed team of developers of mixed technical ability. Early in the project a short survey was conducted as to the most appropriate process, and one particular process (ICONIX) was settled upon.

\section{Open Source software}

One of the project's implicit aims was to investigate the viability of working with freely available Open Source software (OSS). Surveying the available software in this area, it was recognised that no one package exactly met requirements; therefore the approach was taken to build on OSS where possible. The experience of working with OSS has been largely positive, and it certainly should be considered a possible alternative to more traditionally commercial approaches. On the plus side, there is much expertise and enthusiasm in the Open Source community, and many packages are (and have been for some time) mature and established software tools. Having access to a package's source code can also be very useful for a developer hunting down a problem, and often open source developers are responsive to queries and suggestions. However, as with all software, quality can be variable, and large-scale interface changes between versions have occasionally been troublesome. SPP has used OSS in order to avoid re-inventing the wheel and has been keen to add value to existing OSS packages for learning, teaching and research whenever possible in order to contribute to the Open Source community.

In phase II of the project SPP is continuing to contribute to further to the Open Source community by actually rolling out the portal work as OSS. This will involve working more closely with the Open Source Focus (www.oss-watch.ac.uk/) team based in Oxford and will require long-term maintenance.

\section{Dissemination}

Another contribution of the project has been the significant amount of dissemination. Many well-received presentations have been delivered from people right across the project team and which covered many aspects of its work including technical, content-based and managerial elements. A full list of these presentations is available from the SPP web site (www.portal.ac.uk/spp/documents/phase1/).

\section{Conclusions}

The SPP has many beneficiaries: from the $\mathrm{HE}$ and FE communities, web managers and institutions looking at portal implementation to the end-users including students, lecturers, academics and distance learners. It is hoped that these end-users will soon benefit from an improved experience when seeking subject specific information online. They will learn about how to carry out faster and more effective searching, how to store a personal profile resulting in more targeted delivery of content and there will be increase in the ease of access to JISC content. SPP work carries on and in the future there will be more understanding of synergies and integration with those developing their own portals both inside and outside of the JISC IE.

\section{Notes}

1. Hub for biomedical sciences.

2. Hub for engineering. 
3. Hub for humanities.

4. Hub for social sciences, business and law.

5. Hub for physical sciences.

6. Hub for hospitality, leisure, sport and tourism.

7. Hub for arts and creative industries.

8. Hub for geography and the environment.
The Subject Portals Project

\section{Reference}

Guy, M. (2004), "Managing a distributed development project: the Subject Portals Project", available at: www.ukoln.ac.uk/qa-focus/documents/case-studies/case-study-03/ 